\title{
Levantamento dos impactos socioambientais na área do lixão a céu aberto no Município de Corrente, Estado do Piauí, Nordeste do Brasil
}

\section{Patrine Nunes Gomes ${ }^{1,}{ }^{*}$, Marcília Martins da Silva ${ }^{2}$, Luana de Castro Pereira ${ }^{1}$, Luzirany Soares Lopes $^{1}$, Cecília de Souza Carvalho $^{1}$, Raiane Oliveira de Souza ${ }^{1}$ e Estefani Barros Maciel ${ }^{1}$}

${ }^{1}$ Curso de Tecnologia em Gestão Ambiental. Instituto Federal de Educação, Ciência e Tecnologia do Piauí. Campus Corrente. Rua do Campo S/N. Centro. Corrente-PI (CEP 64980-000). *E-mail: patrinenunes12@gmail.com.

${ }^{2}$ Curso de Tecnologia em Gestão Ambiental. Instituto Federal de Educação, Ciência e Tecnologia do Piauí. Campus Corrente. Rua Projetada 6. Nova Corrente. Corrente-PI (CEP 64980-000).

Resumo. Com o decorrer dos anos e o surgimento das indústrias vários problemas foram afetando o mundo, um deles é grande geração de resíduos sólidos e posteriormente a forma como eles são dispostos no meio ambiente. Atualmente, sabe-se que os resíduos quando não recebem uma disposição correta pode ocasionar diversos prejuízos à natureza. Tal geração ocorre devido ao intenso processo de urbanização das cidades e da necessidade das pessoas de consumirem cada vez mais produtos, aumentando assim consequente à quantidade de resíduos. Diante disto, este estudo teve como objetivo verificar os impactos ambientais da área de disposição final de resíduos sólidos do Município de Corrente, Piauí, Nordeste do Brasil. Para realização da pesquisa foi feita visita na área de disposição final dos resíduos do município, onde os impactos foram diagnosticados por meio de avistamento direto, utilizando-se como método de avaliação a Matriz de Impacto de Leopold. Observou-se com a pesquisa que o lixão exerce uma ação negativa, visto que a maioria dos impactos apresenta alto grau na área de disposição final dos resíduos, dentre eles destacam-se o aumento dos processos erosivos, compactação do solo, possível depreciação do lençol freático, emissão de gases do efeito estufa, possível contaminação e redução da biota do solo, redução da capacidade de sustentação da flora, riscos de contaminação dos catadores e presença de vetores de doenças. Com base nisto, conclui-se que é de extrema importância que seja implantado no município um sistema disposição final adequado que possa comportar todos os rejeitos e ainda a implementação da coleta seletiva, a fim de aproveitar os resíduos sólidos recicláveis. Tal ação irá diminuir os impactos ambientais da área e incentivaria a população a separar e dispor melhor os seus resíduos.
Recebido:

$24 / 06 / 2019$

Aceito:

$26 / 08 / 2019$

Disponível on line:

$27 / 08 / 2019$

Publicado:

$31 / 08 / 2019$

Acesso aberto

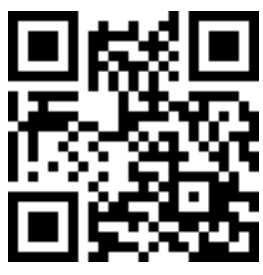

ORCID

(1) 0000-0002-9201-6928 Patrine Nunes Gomes

(ㄱ) 0000-0002-4906-7965

Marcília Martins da

Silva

D) 0000-0001-8814-0478

Luana de Castro

Pereira 
Palavras-chave: Resíduos sólidos; Destinação final; Meio ambiente.

\begin{abstract}
Survey of social and environmental impacts in the sky opened dump area in Corrente Municipality, Piauí State, Northeast Brazil. With the course of the years and the emergence of industries various problems have been affecting the world, one is large generation solid waste and subsequently the way they are disposed in the environment. Nowadays, it is known that waste when it does not receive a correct disposal can cause several damages to nature. Such generation occurs due to the intense urbanization process of the cities and the need of the people to consume more and more products consequently increasing to the amount of residues. In view of this, this study aimed to verify the environmental impacts of the final disposal area of solid waste in the Municipality of Corrente, Piauí State, Northeast Brazil. In order to carry out the research, the final disposal area of the municipal waste was visited, where the impacts were diagnosed through direct sighting using the Leopold Impact Matrix as the evaluation method. Geographic coordinates were also collected through the GPS, to make the location map of the garbage area, and photographic records were also made. It can be observed that the landfill has a negative effect, since most of the impacts present a high degree of final waste disposal, among them: erosion processes, soil compaction, possible depreciation of the soil. water table, emission of greenhouse gases, possible contamination and reduction of the soil biota, reduction of the sustentation capacity of the flora, risks of contamination of the collectors and presence of vectors of diseases. Based on this, it is concluded that it is extremely important that an adequate final disposition system be installed in the municipality, which may include all wastes and the implementation of selective collection, in order to take advantage of recyclable solid waste. Such action will reduce the environmental impacts of the area and encourage the population to separate and dispose of their waste better.
\end{abstract}

Keywords: Solid waste; Final destination; Environment.

\author{
D) 0000-0003-1698-1029 \\ Luzirany Soares Lopes \\ (1) 0000-0003-1362-4077 \\ Cecília de Souza \\ Carvalho \\ D) 0000-0003-3116-115X \\ Raiane Oliveira de \\ Souza \\ 0000-0001-9456-5915 \\ Estefani Barros Maciel
}

\section{Introdução}

Com o decorrer dos anos e o surgimento das grandes cidades e das indústrias, vários problemas ambientais foram afetando o Mundo, um deles é grande geração de resíduos sólidos e posteriormente a forma como eles são dispostos no meio ambiente. Atualmente, sabe-se que os resíduos quando não recebem uma disposição correta ocasionam diversos prejuízos à Natureza. A geração excessiva de resíduos sólidos ocorre devido ao intenso processo de urbanização das cidades e da necessidade das pessoas de consumirem cada vez mais produtos, aumentando assim a quantidade de resíduos.

A formação das cidades, na maioria das vezes sem um planejamento adequado, contribui para o surgimento de vários impactos adversos ao meio ambiente, inclusive a geração de resíduos sólidos que estão veiculados com as atividades da sociedade. Desta forma a grande geração e disposição final inadequada dos resíduos têm sido considerada um dos maiores impactos 
sofridos pelo meio ambiente (Costa et al., 2016).

A degradação do ambiente em decorrência da disposição irregular dos resíduos proporciona impactos tanto ambientais como sociais. Tais problemas têm sido ocasionados tanto pela ausência de recursos para o tratamento $\mathrm{e}$ disposição adequada dos resíduos, como também deficiência nas etapas do gerenciamento: a coleta, o transporte, 0 transbordo, o tratamento e a destinação final ambientalmente adequada dos resíduos sólidos e disposição final ambientalmente adequada dos rejeitos (Costa et al., 2012).

Muitos são os impactos ocasionados pela destinação inadequada dos resíduos sólidos podendo-se elencar a poluição dos recursos hídricos, solo, ar, e ainda a proliferação de vetores que causam doenças como, ratos, moscas entre vários outros. Em sua pesquisa de caracterização de impactos ambientais em lixões a céus aberto Silva et al. (2012), encontraram, por meio de diagnóstico, os seguintes impactos: aumento dos processos erosivos do solo, compactação do solo, proliferação de micro e macrovetores e poluição visual.

Segundo Costa et al. (2016), os responsáveis por fazer a disposição adequada dos resíduos sólidos em uma cidade são as prefeituras, no entanto, existe alguns resíduos especiais, como os pneus, resíduos da saúde, pilhas e baterias, na qual a disposição fica sobre a responsabilidade daquele que o gerou. No Brasil, os resíduos sólidos são dispôstos principalmente nos lixões a céu aberto, mesmo ocasionando grandes impactos ao meio ambiente e à saúde pública.

Além dos lixões, existem outras alternativas para a disposição final de resíduos sólidos, sendo uma delas o aterro controlado, que minimiza os impactos. Para Silva et al. (2012), o aterro controlado tem como finalidade diminuir os impactos causados ao meio ambiente, pois nesta forma de disposição os resíduos ficam confinados por uma camada de material inerte, porém, não possui manta de impermeabilização do solo (Brasil, 2006).

Outra técnica de disposição dos resíduos sólidos é o aterro sanitário, que, segundo Zanini e Lessa (2013), contém grande capacidade de minimizar os impactos ambientais, sendo considerada adequada para dispor os resíduos, isso em decorrência dele possuir mantas impermeáveis resistentes, que diminuem a contaminação dos recursos hídricos e outros equipamentos, como dreno de gases, águas superficiais, captação de chorume e saída para a estação de tratamento.

Silva et al. (2012), ressalta que há a "necessidade de avaliar os reais impactos causados pela prática inadequada de descarga de resíduos a céu aberto". Uma vez que a avaliação propicia o conhecimento sobre seus efeitos e ainda o acompanhamento e controle pelo poder público e pela sociedade. Diante disto, este estudo teve como objetivo verificar os impactos socioambientais da área de disposição final de resíduos sólidos do Município de Corrente, Estado do Piauí, Nordeste do Brasil.

\section{Metodologia}

\section{Área de estudo}

A pesquisa foi realizada na área urbana do Município de Corrente-PI, localizada na Microrregião do Extremo Sul Piauiense, situado na área do bioma Cerrado, encontra-se nas coordenadas geográficas de reefrência $10^{\circ} 26^{\prime} 30^{\prime \prime} \mathrm{S}$ e $45^{\circ} 9^{\prime} 52^{\prime \prime} \mathrm{W}$.

0 Município de Correntes compreende uma área de $3.048 .447 \mathrm{~km}^{2}$, com uma população de 26.575 habitantes (IBGE, 2018) e possui clima tropical subúmido quente. A área de estudo escolhida para realização da pesquisa localiza-se a $11 \mathrm{~km}$ da zona urbana da cidade próximo à rodovia PI-225, que liga o Município de Corrente a ao Município de Parnaguá (Figura 1). 


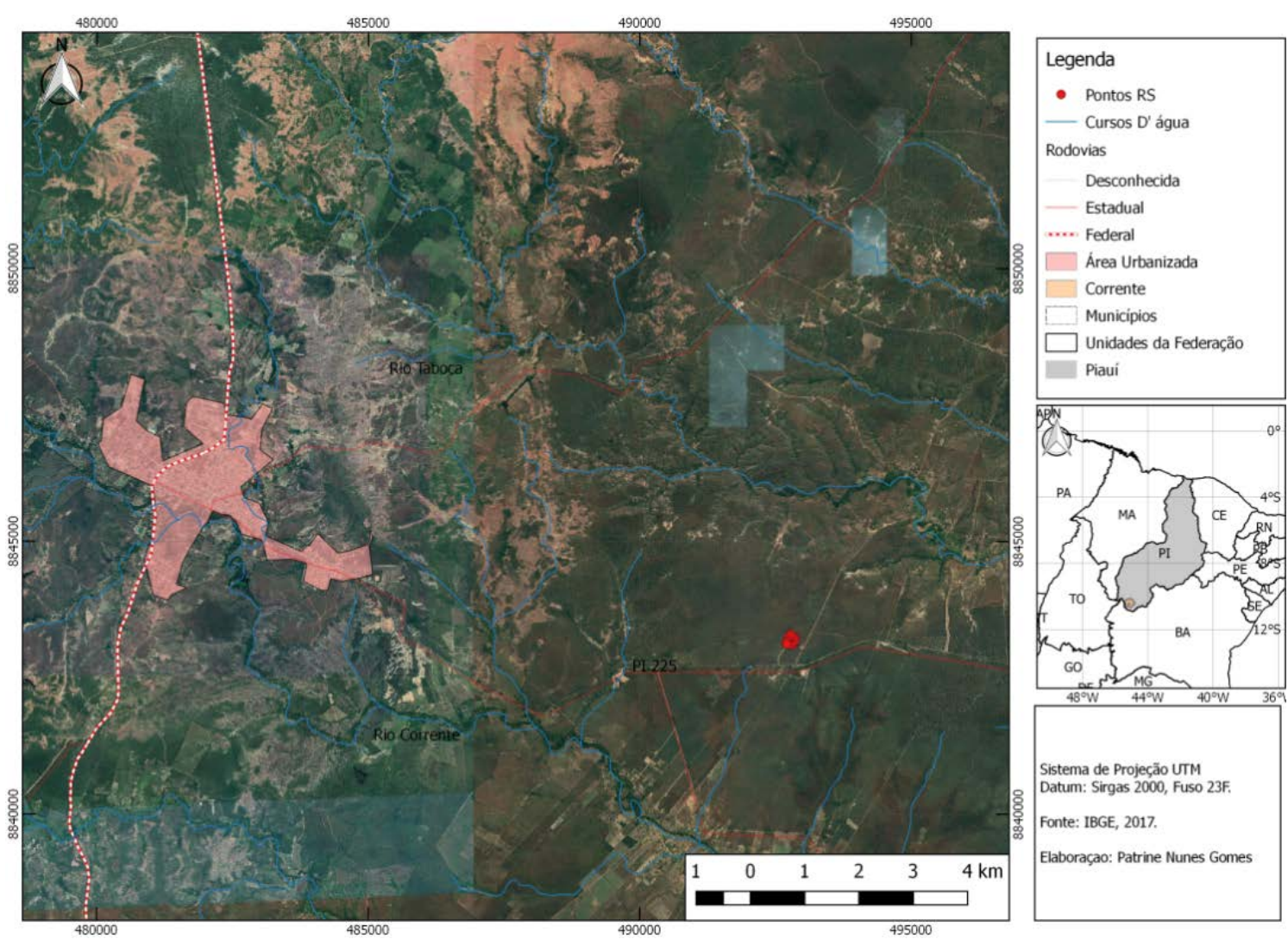

Figura 1. Mapa de localização do município de Corrente-PI. Fonte: IBGE (2017).

\section{Procedimentos metodológicos}

Inicialmente foi feito uma revisão de literatura utilizada para embasar teoricamente a pesquisa. Posteriormente, foi feita uma visita na área de disposição final dos resíduos do município, onde os impactos foram diagnosticados por meio de avistamento direto utilizando-se como método de avaliação a Matriz de Impacto de Leopold et al. (1971). Para Araújo (2015), "esse método permite uma fácil compreensão dos resultados; aborda fatores biofísicos e sociais; acomoda dados qualitativos e quantitativos, além de fornecer boa orientação pra o prosseguimento dos estudos e introduzir multidisciplinaridade".

Segundo Silva et al. (2012), a Matriz de Impacto de Leopold et al. (1971), "foi desenvolvida pela Sociedade Geológica Americana e é tida como um guia para avaliação e preparação de relatórios de impacto ambiental".

Para realização desta pesquisa foram feitas algumas adaptações na matriz referente aos impactos do lixão. Com isso, utilizou-se a Matriz de Impacto qualitativa de Sobral et al. (2007) e Santos (2004), onde os parâmetros qualitativos avaliados são referentes a algumas características (Tabela 1).

Foi feito ainda coleta de coordenadas geográficas por meio do GPS (Global Positioning System) e utilizou-se o QGIS desktop 2.14.8 que consiste em programa de Sistema de Informação Geográfica (SIG), utilizado para confecção do mapa de localização da área do lixão e ainda foram feitos registros fotográficos para melhor evidenciar a área de estudo. 
Tabela 1. Parâmetros qualitativos e características avaliadas.

\begin{tabular}{|c|c|}
\hline \multirow[t]{3}{*}{$\begin{array}{l}\text { FREQUÊNCIA: remete ao padrão de } \\
\text { ocorrência do impacto, que pode ser } \\
\text { caracterizado como: }\end{array}$} & $\begin{array}{l}\text { Temporário (T): quando o efeito do impacto se } \\
\text { manifesta por um determinado tempo após a realização } \\
\text { da ação; }\end{array}$ \\
\hline & $\begin{array}{l}\text { Permanente (Pr): quando uma vez executada a ação os } \\
\text { efeitos continuam a manifestar-se num horizonte } \\
\text { temporal conhecido; }\end{array}$ \\
\hline & $\begin{array}{l}\text { Cíclico (C): quando o efeito se faz sentir em } \\
\text { determinados períodos (ciclos), que podem ser ou não } \\
\text { constatado ao longo do tempo. }\end{array}$ \\
\hline \multirow{2}{*}{$\begin{array}{l}\text { REVERSIBILIDADE: refere-se ao retorno } \\
\text { do fator ou parâmetros ambientais às } \\
\text { condições originais, podendo ser } \\
\text { caracterizado como: }\end{array}$} & $\begin{array}{l}\text { Reversível (Rv): quando cessada a ação o fator } \\
\text { ambiental retorna as condições originais; }\end{array}$ \\
\hline & $\begin{array}{l}\text { Irreversível (Ir): quando cessada a ação o fator } \\
\text { ambiental afetado não retorna as condições originais } \\
\text { pelo menos num horizonte de tempo aceitável pelo } \\
\text { homem. }\end{array}$ \\
\hline \multirow[t]{2}{*}{$\begin{array}{l}\text { EXTENSÃO: é o alcance do impacto, que } \\
\text { pode ser caracterizado como: }\end{array}$} & $\begin{array}{l}\text { Local (L): quando o efeito se circunscreve ao próprio } \\
\text { local da ação; }\end{array}$ \\
\hline & $\begin{array}{l}\text { Regional (Rg): quando o efeito se propaga por uma } \\
\text { área além das imediações da localidade onde se dá a } \\
\text { ação. }\end{array}$ \\
\hline \multirow{3}{*}{$\begin{array}{l}\text { DURAÇÃ0: refere-se ao tempo que o } \\
\text { impacto e seus efeitos persistem no } \\
\text { ambiente, podendo ser caracterizado } \\
\text { com: }\end{array}$} & $\begin{array}{l}\text { Curto prazo (Cp): quando seus efeitos têm duração de } \\
\text { até } 1 \mathrm{~m} \text { ano; }\end{array}$ \\
\hline & $\begin{array}{l}\text { Médio prazo (Mp): quando seus efeitos têm duração } \\
\text { de } 1 \text { a } 10 \text { anos; }\end{array}$ \\
\hline & $\begin{array}{l}\text { Longo prazo (Lp): quando seus efeitos têm duração } \\
\text { de } 10 \text { a } 50 \text { anos. }\end{array}$ \\
\hline \multirow{2}{*}{$\begin{array}{l}\text { ORIGEM: relaciona-se à procedência do } \\
\text { impacto, que pode ser caracterizado } \\
\text { como: }\end{array}$} & $\begin{array}{l}\text { Direta (D): quando resulta de uma simples relação de } \\
\text { causa e efeito; }\end{array}$ \\
\hline & $\begin{array}{l}\text { Indireta (I): quando é uma reação secundária da ação, } \\
\text { ou quando é parte de uma cadeia de reações. }\end{array}$ \\
\hline \multirow{2}{*}{$\begin{array}{l}\text { SENTIDO: refere-se à valoração do } \\
\text { impacto, ou seja, se o impacto é } \\
\text { caracterizado como: }\end{array}$} & $\begin{array}{l}\text { Positivo (P): quando a ação impactante causa melhoria } \\
\text { da qualidade de um parâmetro ambiental; }\end{array}$ \\
\hline & $\begin{array}{l}\text { Negativo (N): quando uma ação causa um dano à } \\
\text { qualidade ambiental. }\end{array}$ \\
\hline \multirow[t]{3}{*}{$\begin{array}{l}\text { GRAU DE IMPACTO: é o critério de } \\
\text { classificação usado para indicar a } \\
\text { gravidade do impacto no meio ambiente, } \\
\text { que pode ser }\end{array}$} & $\begin{array}{l}\text { Baixo (B): quando a utilização dos recursos naturais é } \\
\text { desprezível quanto ao seu esgotamento e à degradação } \\
\text { do meio ambiente e da comunidade, sendo desprezível } \\
\text { e reversível; }\end{array}$ \\
\hline & $\begin{array}{l}\text { Médio (M): quando a utilização de recursos naturais é } \\
\text { considerada, sem que haja possibilidade de } \\
\text { esgotamento das reservas naturais, sendo a degradação } \\
\text { do meio ambiente e da comunidade é reversível, porém } \\
\text { com ações imediatas; }\end{array}$ \\
\hline & $\begin{array}{l}\text { Alto }(\mathbf{A}) \text { : quando a ação provoca a escassez de recursos } \\
\text { naturais, a degradação do meio ambiente e da à } \\
\text { comunidade, não tendo muitas probabilidades de } \\
\text { reversibilidade. }\end{array}$ \\
\hline
\end{tabular}

Fonte: Santos (2004); Sobral et al. (2007). 


\section{Resultados e discussão}

Os resíduos sólidos do município são coletados diariamente com exceção apenas dos sábados e domingos, onde a coleta é feita por meio de caminhões da empresa terceirizada responsável por prestar este serviço. Em seguida os resíduos são encaminhados para o lixão da cidade que fica a $11 \mathrm{~km}$ da zona urbana.

Durante visita ao lixão foi possível observar grande quantidade de resíduos, tais como papelão, vidro, pneu, plástico, alumínio, resíduos orgânicos entre outros (Figura 1). Segundo Silva e Santos (2016), os materiais mais encontrados e coletados são papelão, plástico, papel, alumínio e vidro.

Observou-se que dentre estes resíduos uma presença marcante de pneus e plásticos, conforme mostra a foto 1 , onde a grande quantidade se pneus se dá devido na cidade haver muitas oficinas de automóveis/motos, que por não fazem a destinação correta dos destes resíduos acabam encaminho-os ao lixão.
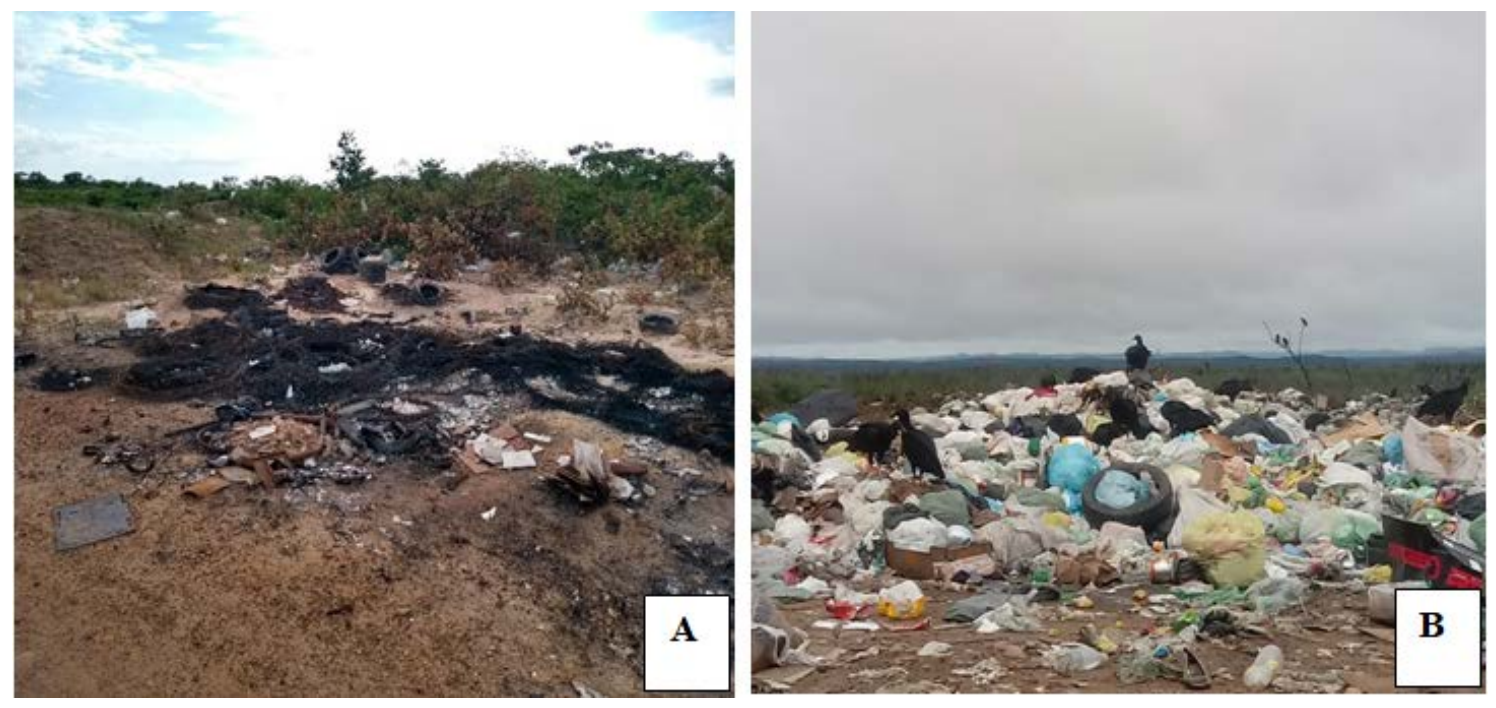

Figura 1. Resíduos sólidos dispostos no lixão de Corrente-PI.

Em relação aos Resíduos Sólidos de Serviço de Saúde (RSSS), gerados no hospital de Corrente-PI, não foram observados a presença destes no lixão, onde isto não acontece devido estes resíduos serem coletados por uma empresa que encaminha o material para a capital do estado para então receberem uma destinação final adequada, que no caso desse tipo é incineração, isso de acordo funcionários do hospital.

Segundo Nunes et al. (2012), "os resíduos hospitalares que necessitam de um tratamento específico, uma vez que representam um grande perigo a saúde, uma vez que podem estar contaminados com microrganismos causadores de doenças" (Figura 2).

Foi possível observar ainda durante a visita que a disposição destes resíduos ocasiona a proliferação de insetos e vetores que podem causa doenças como, por exemplo, moscas, mosquitos e urubus, como mostram a foto 2. Vetores estes que podem ser transmissores de doenças tanto para os catadores ali presentes quanto para os trabalhadores que fazem a coleta dos resíduos na cidade e em seguida os encaminha para o lixão. 


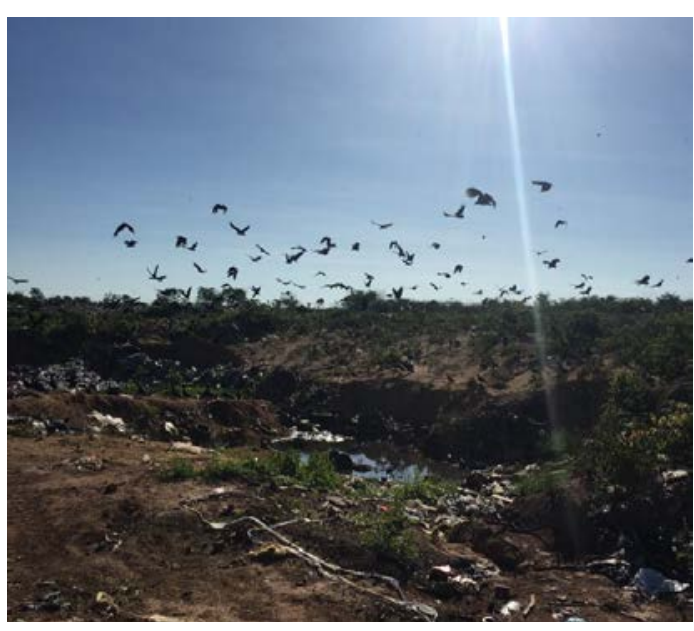

Figura 2. Presença de vetores que causam doenças lixão do Município de Corrente-PI.

Além da proliferação dos insetos observou-se também uma grande modificação na paisagem do local bem o aumento do processo erosivo, compactação do solo, redução e estress da fauna e flora e emissão de gases como o metano $\left(\mathrm{CH}_{4}\right)$, dióxido de carbono $\left(\mathrm{CO}_{2}\right)$, que são os que mais aumentam o efeito estufa.

Quando acelerados os processos erosivos ocasiona uma alteração no ambiente, onde se dá devido relação de diversos fatores como, por exemplo, $\mathrm{o}$ relevo, as condições climáticas, os tipos de solo e suas ocupações e ainda a cobertura vegetal (Sánchez, 2008). Para Costa et al. (2016), "esses impactos afetam a qualidade ambiental e promovem um desequilíbrio ecológico para os animais vivos que habitam nessa área, especificamente no que diz respeito à fauna e flora local".

Os impactos avaliados foram separados de acordo, como os aspectos físicos que estão relacionados ao clima, hidrografia, solo, relevo dentre outros, o meio biótico com relação à fauna e flora e por fim o meio antrópico que envolve os aspectos da sociedade (Tabela 1 ).

Conforme mostra a Tabela 1, o lixão exerce uma ação negativa, visto que a maioria dos impactos apresenta alto grau na área de disposição final dos resíduos, dentre eles destacam-se: o aumento dos processos erosivos, compactação do solo, possível depreciação do lençol freático, emissão de gases do efeito estufa, possível contaminação e redução da biota do solo, redução da capacidade de sustentação da flora, riscos de contaminação dos catadores e presença de vetores de doenças.

Em relação aos impactos do meio físico, como o aumento dos processos erosivos, compactação do solo, possível depreciação do lençol freático e emissão de gases do efeito estufa, foram avaliados como sendo impactos permanentes visto que, quando realizada a ação os efeitos dos impactos se revela numa proporção temporal conhecida. 
Tabela 1. Matriz de avaliação dos impactos ambientais do lixão do Município de Corrente-PI.

\begin{tabular}{|c|c|c|c|c|c|c|c|c|c|c|c|c|c|c|c|c|c|}
\hline \multirow{3}{*}{ Impactos ambientais } & \multicolumn{17}{|c|}{ Características } \\
\hline & \multicolumn{3}{|c|}{ Frequência } & \multicolumn{2}{|c|}{ Reversibilidade } & \multicolumn{2}{|c|}{ Extensão } & \multicolumn{2}{|c|}{ Duração } & \multicolumn{2}{|c|}{ Origem } & \multicolumn{3}{|c|}{ Sentido } & \multicolumn{3}{|c|}{$\begin{array}{l}\text { Grau de } \\
\text { Impacto }\end{array}$} \\
\hline & $\mathrm{T}$ & $\mathrm{Pr}$ & $\mathrm{C}$ & Rv & Ir & $\mathrm{L}$ & $\mathrm{R}$ & $\mathrm{Cp}_{\mathrm{p}}$ & $\mathrm{Mp}$ & Lp & $\mathrm{D}$ & $\mathrm{I}$ & $\mathrm{P}$ & $\mathrm{N}$ & $\mathrm{B}$ & $\mathrm{M}$ & $\mathrm{A}$ \\
\hline & \multicolumn{17}{|c|}{ Meio Físico } \\
\hline 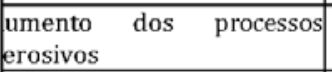 & & $\mathrm{x}$ & & $\mathrm{x}$ & & $\mathrm{X}$ & & & $\mathrm{x}$ & $\mathrm{x}$ & & & $\mathrm{x}$ & & & $\mathrm{X}$ & \\
\hline Compactação do solo & & $\mathrm{X}$ & & & $\mathrm{X}$ & $X$ & & $x$ & & & $\mathrm{X}$ & & $\mathrm{X}$ & & & $\mathrm{X}$ & \\
\hline $\begin{array}{l}\text { Possível depreciação do } \\
\text { lençol freático }\end{array}$ & & $\mathrm{x}$ & & $\mathrm{x}$ & & & $\mathrm{x}$ & $\mathrm{x}$ & & $\mathrm{x}$ & & & $\mathrm{x}$ & & & $\mathrm{x}$ & \\
\hline \begin{tabular}{|l|} 
Emissão de gases de efeito \\
estufa (biogás)
\end{tabular} & & $\mathrm{X}$ & $\mathrm{X}$ & $\mathrm{X}$ & & & $\mathrm{x}$ & $\mathrm{X}$ & & $\mathrm{X}$ & & & $\mathrm{X}$ & & & $\mathrm{x}$ & \\
\hline $\begin{array}{l}\text { Possível contaminação do } \\
\text { solo }\end{array}$ & $\mathrm{x}$ & & & $\mathrm{x}$ & & $\mathrm{x}$ & & & $\mathrm{x}$ & $\mathrm{x}$ & & & $\mathrm{x}$ & & & $\mathrm{x}$ & \\
\hline \multirow[t]{2}{*}{ Emissões de odores } & & & & $\mathrm{X}$ & & $\mathrm{X}$ & & $\mathrm{X}$ & & $\mathrm{x}$ & & & $\mathrm{X}$ & & $\mathrm{x}$ & & \\
\hline & \multicolumn{17}{|c|}{ Meio Biótico } \\
\hline Redução da biota do solo & & $\mathrm{x}$ & & & $\mathrm{X}$ & $\mathrm{X}$ & & & & $\mathrm{x}$ & $\mathrm{X}$ & & & $\mathrm{X}$ & & & $\mathrm{X}$ \\
\hline $\begin{array}{l}\text { Redução da capacidade de } \\
\text { sustentação da flora }\end{array}$ & $\mathrm{x}$ & & & & $\mathrm{x}$ & $\mathrm{x}$ & & & $\mathrm{x}$ & & $\mathrm{x}$ & & & $\mathrm{x}$ & & $\mathrm{x}$ & \\
\hline $\begin{array}{|ll|}\begin{array}{l}\text { Redução } \\
\text { biodiversidade nativa }\end{array} & \text { da } \\
\end{array}$ & $\mathrm{X}$ & & & $\mathrm{x}$ & & $\mathrm{x}$ & & & & $\mathrm{x}$ & $\mathrm{x}$ & & & $\mathrm{x}$ & & & $\mathrm{x}$ \\
\hline \multirow[t]{2}{*}{ Stress da fauna local } & $\mathrm{x}$ & & & $\mathrm{x}$ & & $x$ & & $x$ & & & $\mathrm{x}$ & & & $\mathrm{x}$ & $\mathrm{x}$ & & \\
\hline & \multicolumn{17}{|c|}{ Meio Antrópico } \\
\hline $\begin{array}{|ll|}\begin{array}{l}\text { Poluição de áreas } \\
\text { circunvizinhas }\end{array} & \\
\end{array}$ & $\mathrm{x}$ & & & $\mathrm{X}$ & & $\mathrm{x}$ & & $\mathrm{x}$ & & & & $x$ & & $\mathrm{x}$ & & $\mathrm{x}$ & \\
\hline $\begin{array}{l}\text { Risco de contaminação dos } \\
\text { catadores }\end{array}$ & & & $\mathrm{x}$ & $\mathrm{x}$ & & $\mathrm{x}$ & & $\mathrm{X}$ & & & $\mathrm{x}$ & & & $\mathrm{X}$ & & & $\mathrm{X}$ \\
\hline $\begin{array}{|llll|}\begin{array}{l}\text { Presença } \\
\text { doenças }\end{array} & \text { vetores de } \\
\end{array}$ & $\mathrm{X}$ & & & $\mathrm{x}$ & & $\mathrm{x}$ & & $\mathrm{X}$ & & & $\mathrm{x}$ & & & $\mathrm{x}$ & & & $\mathrm{x}$ \\
\hline Poluição visual & $\mathrm{X}$ & & & $\mathrm{X}$ & & $\mathrm{X}$ & & $\mathrm{X}$ & & & $\mathrm{X}$ & & & $\mathrm{X}$ & & $\mathrm{X}$ & \\
\hline $\begin{array}{l}\text { Desvalorização da área ao } \\
\text { entorno }\end{array}$ & $\mathrm{x}$ & & & $\mathrm{x}$ & & $\mathrm{x}$ & & & $\mathrm{x}$ & & & $\mathrm{x}$ & & $x$ & & $\mathrm{x}$ & \\
\hline $\begin{array}{l}\text { Geração de emprego aos } \\
\text { catadores }\end{array}$ & $\mathrm{X}$ & & & & & $\mathrm{x}$ & & & $\mathrm{x}$ & & & $\mathrm{x}$ & $x$ & & & $\mathrm{x}$ & \\
\hline
\end{tabular}

Legenda: T - Temporário; Pr - Permanente; C - Cíclico; Rv - Reversível; Ir - Irreversível; L - Local; R Regional; Cp - Curto Prazo; Mp - Médio Prazo; Lp - Longo Prazo; D - Direta; I - Indireta; P - Positiva; N - Negativa; B - Baixa; M - Médio; A -Alto.

E no que diz respeito ao meio biótico alguns impactos podem ser reversíveis. Conforme os dados discriminados na tabela 1, é possível observar que a maioria dos impactos são reversíveis, isso mediante ao uso de técnicas para recuperar a área afetada, bem como o isolamento e retirada dos resíduos sólidos causadores destes impactos. E apenas três impactos foram considerados irreversíveis, com redução da biota do solo, redução da capacidade de sustentação da flora e compactação solo, que acontece devido movimentação frequente dos veículos pesados que descarregam os resíduos coletados na cidade.
O isolamento da área e retirada do fator de degradação representam a ação inicial de todo e qualquer projeto de restauração, pois é notório que sem essas ações, nenhuma outra será realizada com sucesso. Assim, o objetivo fundamental dessas duas ações é evitar a geração de novas degradações na área. 0 isolamento pode ocorrer com a implantação de cercas, além do essencial desenvolvimento de Educação Ambiental com os moradores próximos da área degradada e, principalmente, com a população da cidade (Silva, et al., 2012). 
Já os impactos do meio antrópico grande maioria se encontram com médio grau de impacto. E em relação ao sentido dos impactos quase todos foram considerados negativos com exceção da geração de emprego para os catadores presentes no lixão, que na realização de suas atividades acabam ficando diretamente expostos a riscos de contrair doenças devido à proliferação de vetores. Além destes impactos outros que também devem ser ressaltados são de poluição das áreas circunvizinhas, desvalorização das áreas ao entorno, bem como a poluição visual.

Para Araújo (2015), os resíduos sólidos podem provocar inúmeros impactos ao meio ambiente quando dispostos de forma irregular como, por exemplo, poluição dos corpos hídricos, do ar e solo, perda da qualidade de vida, fortes odores, desvalorização da área ao entorno, proliferação de vetores transmissores de doenças dentre vários outros, que impedi a população em se interessar por estas áreas.

Já em se tratando da duração, grande parte dos impactos foram considerados de médio e curto prazo, pois estes possuem efeitos de 1 a 10 anos e de apenas um ano, respectivamente. Já na questão de origem a maioria são impactos diretos como, por exemplo, a poluição visual.

E por fim, em relação à extensão dos impactos na sua maioria são considerados de nível "local", visto que são impactos que se limitam ao município de Corrente-PI, e somente a possível depreciação do lençol freático e a emissão de gases do efeito estufa foram considerados regional, isso em decorrência dos seus efeitos se propagarem por áreas além dos limites do município em que se localiza o lixão.

A emissão de gases ocorre devido à produção de gás por parte da decomposição da matéria orgânica e em virtude dos resíduos serem queimados com as finalidades de reduzir o volume, tal fato agrava diretamente o do efeito estufa. E isso, consequentemente, ocasionam riscos à saúde das pessoas e a diminuição a fauna e flora na área (Figura 3).

De acordo Souza (2009), alguns gases de lixões, provenientes da decomposição da matéria orgânica, como é o caso do gás metano que um dos agravantes do efeito estufa, promovendo assim o aquecimento global intensificado e ocasiona riscos à saúde pública. "Além disso, em altas concentrações, pode causar incêndios ou explosões no lixão ou em áreas vizinhas ao mesmo" Souza (2009).

No estudo realizado por Costa et al. (2016), sobre impactos ambientais de lixão a céu aberto em Cristalândia-PI, foi encontrado os mesmos resultados no que diz respeito à queima para diminuir o volume dos resíduos:

A grande maioria dos resíduos dispostos no lixão é submetida à queima, sendo uma estratégia utilizada para reduzir a quantidade de resíduos acumulados no local. Esse processo de queima acaba agredindo ainda mais o meio ambiente, uma vez que a combustão desses resíduos emite grandes quantidades de gases de efeito estufa, contribuindo com a poluição do ar. Além da própria deposição dos resíduos no lixão, o processo de queima também contribui para a redução da biodiversidade, uma vez que o fogo afasta os animais e afeta os vegetais ali presentes (Costa et al., 2016).

Sabe-seque atualmente já existem metidas mitigadoras de impactos, diante disso, foi elencado para cada impacto negativo identificado na área de disposição final do município de Corrente-PI, medidas mitigadoras que poderiam sem implementadas (Tabela 2). 

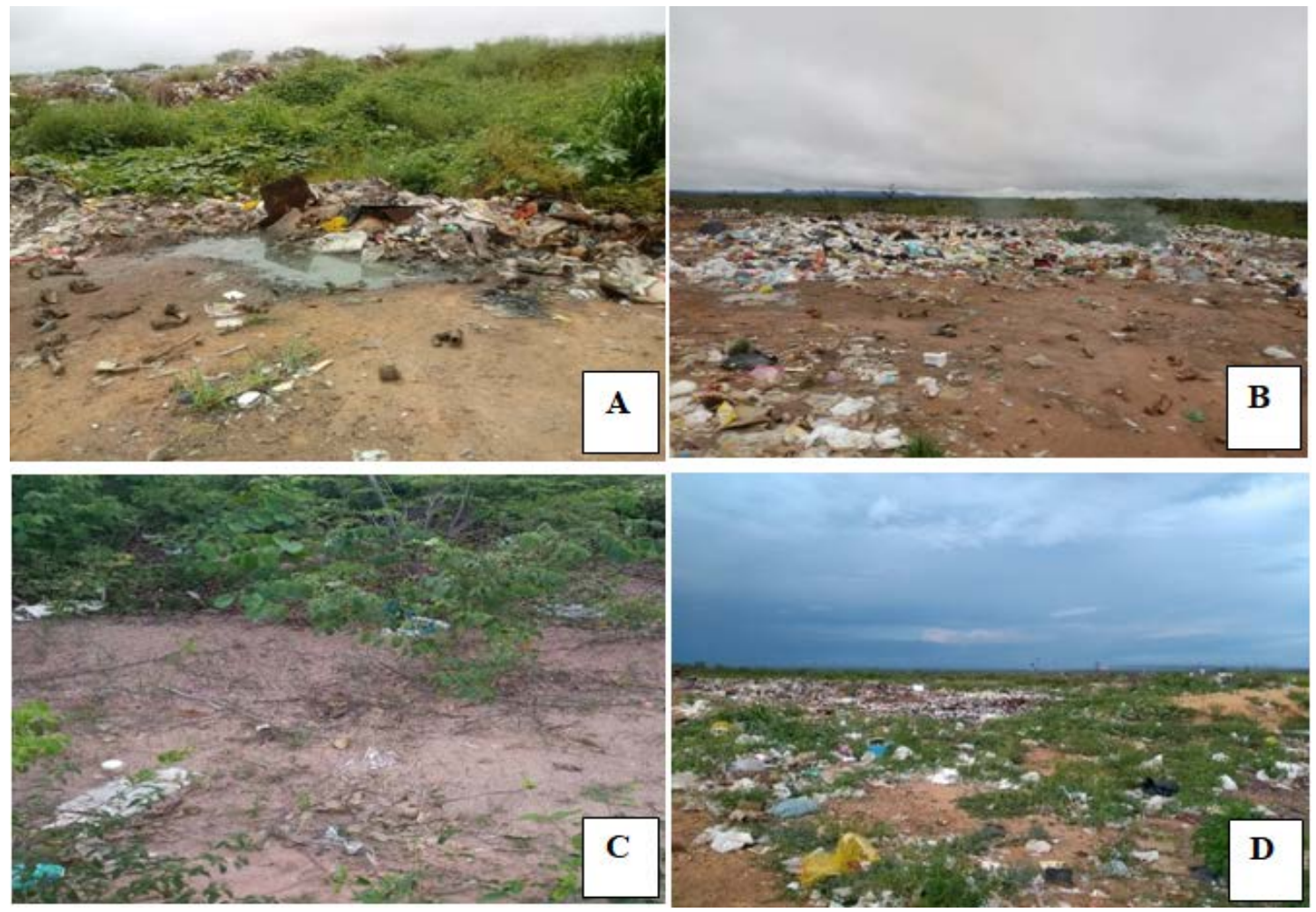

Figura 3. Impactos ambientais na área de disposição de Corrente-PI.

Tabela 2. Medidas mitigadoras para os impactos identificados na área de disposição final de resíduos sólidos (lixão) do Município de Corrente-PI.

\begin{tabular}{|c|c|c|}
\hline Aspectos & Impactos & Medidas mitigadoras \\
\hline \multirow{4}{*}{$\begin{array}{l}\text { Meio } \\
\text { Físico }\end{array}$} & $\begin{array}{l}\text { Aumento dos processos } \\
\text { erosivos }\end{array}$ & Cobertura do solo com espécies nativas da área \\
\hline & Compactação do solo & $\begin{array}{l}\text { "Descompactação do solo mediante o uso de } \\
\text { escarificador (compactação superficial), subsolador } \\
\text { (compactação profunda), seguido de gradagem } \\
\text { pesada (destorroamento) e nivelamento do solo" } \\
\text { (Alheiros, 2009). }\end{array}$ \\
\hline & $\begin{array}{lcr}\text { Possível } & \text { depreciação } & \text { do } \\
\text { lençol } & \text { freático } & \text { e } \\
\text { contaminação do solo } & \\
\end{array}$ & Seleção dos resíduos dispostos \\
\hline & $\begin{array}{l}\text { Emissão de gases do efeito } \\
\text { estufa e de odores }\end{array}$ & $\begin{array}{l}\text { "Implantação de cortina vegetal e regulagem de } \\
\text { motores para as máquinas para minimizara poluição } \\
\text { do ar por gases e ruídos" (Nagalli, 2005). }\end{array}$ \\
\hline \multirow[t]{2}{*}{$\begin{array}{c}\text { Meio } \\
\text { Biótico }\end{array}$} & $\begin{array}{l}\text { Redução da capacidade de } \\
\text { sustentação da flora, perda de } \\
\text { biodiversidade e stress da } \\
\text { fauna local }\end{array}$ & $\begin{array}{l}\text { Criação de um novo habitat próximo ao lixão através } \\
\text { do plantio de espécies vegetais nativas e que sejam } \\
\text { atrativas aos animais (frutíferas), (Nagalli, 2005) }\end{array}$ \\
\hline & Redução da biota do solo & $\begin{array}{l}\text { Descompactação do solo e possível drenagem do } \\
\text { chorume que causa essa redução }\end{array}$ \\
\hline
\end{tabular}


Tabela 2. Medidas mitigadoras para os impactos identificados na área de disposição final de resíduos sólidos (lixão) do Município de Corrente-PI.

\begin{tabular}{|c|c|c|}
\hline Aspectos & Impactos & Medidas mitigadoras \\
\hline \multirow{4}{*}{$\begin{array}{l}\text { Meio } \\
\text { Antrópico }\end{array}$} & $\begin{array}{l}\text { Poluição das áreas } \\
\text { circunvizinhas } \\
\text { desvalorização das áreas ao } \\
\text { entorno }\end{array}$ & $\begin{array}{l}\text { Recuperação da área de disposição após isolamento } \\
\text { da área (Nagalli, 2005). }\end{array}$ \\
\hline & $\begin{array}{l}\text { Risco de contaminação aos } \\
\text { catadores }\end{array}$ & $\begin{array}{l}\text { "Cercamento da área e sistema de segurança e } \\
\text { controle, Implementação de Programa de Coleta } \\
\text { Seletiva junto à população e Implementação de } \\
\text { Programas de Educação Ambiental" } \\
\text { (Nagalli, 2005). }\end{array}$ \\
\hline & Poluição visual & Recobrimento dos resíduos sólidos \\
\hline & $\begin{array}{l}\begin{array}{l}\text { Presença de vetores } \\
\text { doença }\end{array} \\
\text { de }\end{array}$ & Recobrimento dos resíduos sólidos \\
\hline
\end{tabular}

\section{Conclusão}

Diante dos impactos aqui avaliados por meio do método de matriz constatou-se que o lixão de Corrente-PI possui grande potencial de degradação, e que os impactos prejudicam o meio ambiente de maneira negativa ocasionando o desequilíbrio da natureza.

Verificou-se ainda que, o lixão exerce uma forte ação negativa em virtude da maioria dos impactos serem de alto grau, em que se destaca: o aumento dos processos erosivos, compactação do solo, possível depreciação do lençol freático, emissão de gases do efeito estufa, possível contaminação e redução da biota do solo, redução da capacidade de sustentação da flora, riscos de contaminação dos catadores e presença de vetores de doenças.

E foi possível observar ainda que a maioria dos impactos são reversíveis, isso quando se faz recuperação da área afetada. Diante disto seria de suma importância que o município viesse a adotar medidas com as elencadas no quadro 2 para minimizar esses impactos que são tão prejudiciais para o meio ambiente e a sociedade.

Com base nos dados aqui apresentados, conclui-se que é de extrema importância que seja implantado no município um sistema disposição final adequado que possa comportar todos os rejeitos e ainda a implementação da coleta seletiva, a fim de aproveitar os resíduos sólidos recicláveis. Tal ação irá diminuir os impactos ambientais da área e incentivaria a população a separar e dispor melhor os seus resíduos.

\section{Conflito de interesses}

Os autores declaram não haver conflito de interesses.

\section{Referências}

Alheiros, M. M. Projeto Ambiental: medidas mitigadoras/compensatórias e passivo ambiental do Projeto Pontal, PE. Recife: CPRH, 2009.

Araújo, T. B. Avaliação de impactos ambientais em um lixão inativo no Município de Itaporanga-PB. Campina Grande: Universidade Estadual da Paraíba, 2015. (Monografia de graduação).

Brasil. Fundação Nacional de Saúde. Manual de saneamento. 3. ed. rev. Brasília: Fundação Nacional de Saúde, 2006.

Costa, L. E. B.; Costa, S. K.; Rego, N. A. C.; Silva Junior, M. F. Gravimétrica dos resíduos sólidos urbanos domiciliares e perfil socioeconômico no Município de Salinas, Minas Gerais. Revista Ibero-Americana de Ciências Ambientais, v. 3, n. 2, p. 73-90, 2012. 
Costa, T. G. A.; Iwata, B. F.; Castro, C. P.; Coelho, J. V.; Clementino, G. E. S.; Cunha, L. M. Impactos ambientais de lixão a céu aberto no Município de Cristalândia, Estado do Piauí, Nordeste do Brasil. Revista Brasileira de Gestão Ambiental e Sustentabilidade, v. 3, n. 4 , p.79-86, 2016. https://doi.org/ 10.21438/rbgas.030408

IBGE - Instituto Brasileiro de Geografia e Estatíticas. Corrente-PI. IBGE Cidades. 2018. Disponível em: <https://cidades.ibge.gov.br/ brasil/pi/corrente/panorama>. Acesso em: 06 maio 2019.

IBGE - Instituto Brasileiro de Geografia e Estatísticas. Base cartográfica contínua do Brasil, escala 1:250.000 bc250. Rio de Janeiro: IBGE, 2017. Disponível em: <https://ww2.ibge.gov.br/home/mapa_site/ mapa_site.php\#geociencias>. Acesso em: 06 maio 2019.

Leopold, L. B.; Clarke, F. E.; Hanshaw, B. B.; Balsley, J. R. A procedure for evaluating environmental impact. Washington: United States Department of the Interior, Geological Survey, 1971. (Geological Survey Circular, 645). Disponível em: <http://eps.berkeley. edu/people/lunaleopold/(118) A Procedure for Evaluating Environmental Impact.pdf $>$. Acesso em: 28 mar. 2019.

Nagalli, A. Diagnóstico e avaliação dos impactos ambientais de aterros de disposição de resíduos no Estado do Paraná: estudo de caso dos municípios de Jacarezinho e Barra do Jacaré. Curitiba: Universidade Federal do Paraná, 2005. (Dissertação de mestrado).

Nunes, B. J. M; Silva, N. M. R; Oliveira, F. S. O. Avaliação do manejo e descarte de resíduos hospitalares em Teresina, PI. Anais do VIII Congresso Norte Nordeste de Pesquisa e Inovação (CONNEPI), Palmas, Tocantins, 2012.

Sanchez, L.E. Avaliação de impacto ambiental: conceitos e métodos. São Paulo: Oficina de Textos, 2008.

Santos, R. F. Planejamento ambiental: teoria e prática. São Paulo: Oficina de textos. 2004.

Silva, A. P. P.; Santos, G. O. (Re)conhecimento das condições de vida dos catadores autônomos de materiais reutilizáveis e recicláveis do Centro de Fortaleza. Revista Tecnologia, v. 37, n. 1/2, p. 19-36, 2016.

Silva, S. A. F.; Aragao, M. H. S.; Silva, G. A. B.; Silva, T. S.; Almeida, M. M.; Souza, N. C. Caracterização de impactos ambientais causados por um vazadouro na Cidade de Mogeiro-PB. Anais do I Encontro Nacional de Educação, Ciência e Tecnologia da UEPB, v. 1, n. 1, 2012.

Sobral, I. S.; Santana, R. K. O.; Gomes, L. J.; Ribeiro, G. T.; Santos, J. R. Avaliação dos impactos ambientais no Parque Nacional Serra de Itabaiana-SE. Caminhos de Geografia, v. 8, n. 24, p. 102-110, 2007.

Souza, G. A. Estimativa da produção de biogás no antigo lixão do Itacorubi, Floriaópolis-SC. Floriaópolis: Universidade Federal de Santa Catarina, Centro Tecnológico, 2009. (Monografia de graduação).

Zanini, S. R. D.; Lessa, V. N. Gestão de resíduos sólidos: o resíduo urbano e sua alocação no Município de Pelotas. Revista Eletrônica Academicus, v. 1, n. 1, p. 25-42, 2013. 